\title{
Energy dissipation from vibrating floor slabs due to human-structure interaction
}

\author{
James M.W. Brownjohn \\ Nanyang Technological University, School of Civil \\ and Structural Engineering, 50 Nanyang Avenue, \\ Singapore 639798 \\ Fax: +65 7910676; E-mail: cjames@ntu.edu.sg
}

Received 20 December 2000

Revised 11 May 2001

Lightweight pre-cast flooring systems using post-tensioning to increase strength but not stiffness are increasingly popular, and vibration serviceability problems tend to govern design of such floors where human occupants are increasingly concerned with vibrations. At the same time as inducing response, stationary human observers can also participate in the response as mitigating influence and it is clear that a human behaves as a highly effective damper, even when seated.

Experiments were done to study energy flow and storage in a 1.2 tonne vibrating concrete plank with a human occupant. Results showed that damping could increase to as much as $10 \%$ of critical, accompanied by frequency shifts (usually decreases) in the slab apparent resonant frequency, depending on occupant posture. Simple lumped mass mathematical models were also used to study the vibrating humanstructure system through dynamic simulations, corroborating the findings.

Further corroboration was provided from measurements on a prototype full-scale floor slab occupied by several hundred people who were either jumping or sitting. Modal analysis of vibration response signals showed that normal floor resonance associated with jumping at a sub-harmonic of the floor natural frequency was almost completely damped out by the passive (seated) people.

Keywords: Whole body vibration, damping, structure, floor

\section{Introduction}

The traditional role of humans as participants in the dynamic behaviour of a structure has been as a source of dynamic loading in the form of footfall-induced excitation. Fourier series are used to describe such loading and it is considered in at least one structural de- sign code [4] that walking, jumping or dancing human occupants do not affect structural frequency by adding mass. However, recent research [6] has considered the floor structures with human occupants participating as a passive part of the dynamic system.

The demand for column-free floors leads to use of lightweight floor systems. These may be composite i.e. a concrete slab cast over a framework of steel beams, or they may be entirely concrete but with post-tensioning through steel cables to enable the concrete to function entirely as a compression element. The concrete may also be an assembly of hollow pre-cast elements. Such floors tend to be relatively light and have relatively low damping.

The two issues become connected when considering humans present on lightweight slabs vibrating vertically in response to transient loads caused by, e.g. other people walking past or jumping on the same floor, and the question is: Exactly how does the presence of a stationary human body affect the dynamic behaviour of a flooring system?

Ji and Ellis [6] showed that the effect can be considered with the human behaving as a one-degree of freedom system rather than a simple added mass and that the presence of people can improve damping capacity of a floor [5]. At its simplest the human body behaves as a mass-spring-damper system, at its most complex when used to study behaviour of limbs and other appendages, the body is considered as multidegree of freedom system [7,8]. The models suggested are all passive and linear yet it is obvious that active and/or non-linear mechanisms exist under certain circumstances of excessive vibration in a manner so as to reduce vibration of structure and human.

The identification of non-linear or active elements of human participation in structural vibrations is an ongoing study but the end result is usually seen in two forms: a moderate shift in structure natural frequency and a not so moderate increase in total damping capacity. Damping is energy dissipation and since the desirable end result of human participation is to help control vibration by energy dissipation it is natural to track energy flow in a vibrating human-structure system. 


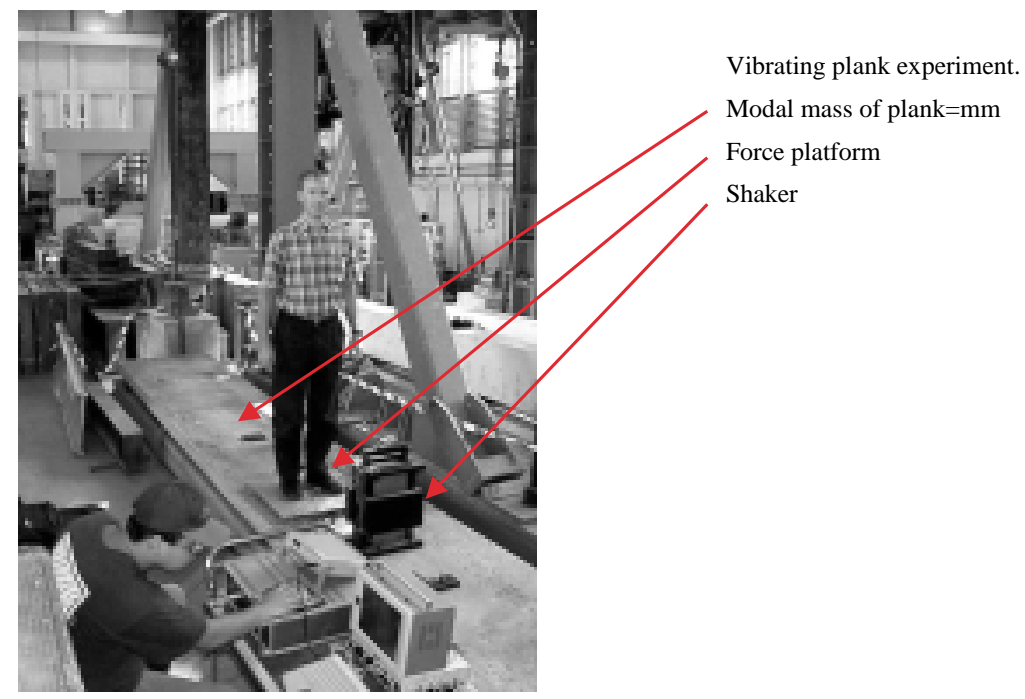

Fig. 1. Vibrating plank experiment.

\section{Laboratory study}

Figure 1 shows a laboratory experiment used to examine energy flow in a vibrating human-structure system. The aim was to study energy transfer by measuring the instantaneous power supplied by a power source (shaker), the instantaneous power transmitted to a human occupant on a plank and the power loss through internal friction in the plank, dependent on the concrete damping capacity.

A 1.2 tonne $7 \mathrm{~m}$ by $1 \mathrm{~m}$ by $75 \mathrm{~mm}$ prestressed concrete plank was simply supported $0.5 \mathrm{~m}$ from each end and forced to vibrate by an APS Dynamics long stroke shaker sitting on the plank and operating in reaction mode. The shaker excitation was a 'chirp' Voltage signal $V(t)$, which is a time-varying sinusoidal signal of finite duration repeating over a cycle of duration $T$ seconds, during which the frequency of the signal varies linearly between minimum and maximum values $f_{\min }, f_{\max }$. The chirp signal provides a broadband excitation while ensuring a high signal to noise ratio in the response, and is ideal for providing the best frequency response data in the shortest time. The chirp signal takes the form:

$$
\begin{aligned}
V(t)= & V_{\max } \sin 2 \pi t \\
& {\left[f_{\min }+(1-t / T)\left(f_{\max }-f_{\min }\right)\right] . }
\end{aligned}
$$

The shaker is essentially a large solenoid and the reaction in the armature of the force on the (moving) armature core with mass $m_{c}$ is transmitted to the shaker support on the plank. Due to the characteristics of the shaker there is a linear relationship between force on the plank and supply Voltage, and to avoid 'leakage' in frequency domain analysis of finite records the Voltage (hence shaker force) signal is tapered at the start and end of each cycle. Figure 2 (top plot) shows part of one cycle of the shaker force $F_{\text {shaker }}$, obtained by core acceleration signal $a_{c}$ through $f_{\text {shaker }}=m_{c} \times a_{c}$.

Figure 3 shows the schematic arrangement and the four signals recorded. Subjects stood on a straingauged metal platform close to the midspan of the plank. Although rather noisy, the strain gauges at least provided a measure of force transmitted $F_{\text {platform }}$ and phase angle with velocity (of the occupant) $v_{\text {platform, }}$ the latter obtained indirectly from integration of the platform acceleration signal ( $\left.a_{\text {platform }}\right)$. Plank velocity at the shaker support $v_{\text {plank }}$ was also obtained from an accelerometer. Kinetic energy of the plank was available from modal mass and plank velocity. Linear viscous damping, assumed to be effective in the plank, causes a percentage of total stored energy (kinetic plus potential) to be lost through friction every cycle.

A sequence of experiments was done using a subject sitting on a plastic chair, or standing erect, with knees slightly bent or knees very bent, also with a solid mass equivalent to the subject. In each case a chirp signal sweeping within range $2-20 \mathrm{~Hz}$ over 40.96 seconds was used. Figure 2 also shows the platform acceleration and force $F_{\text {platform }}$ as the shaker passes through the fundamental mode of the plank at around $3 \mathrm{~Hz}$. Figure 4 shows the frequency response function (FRF) data around the first resonance, for the different postures, 

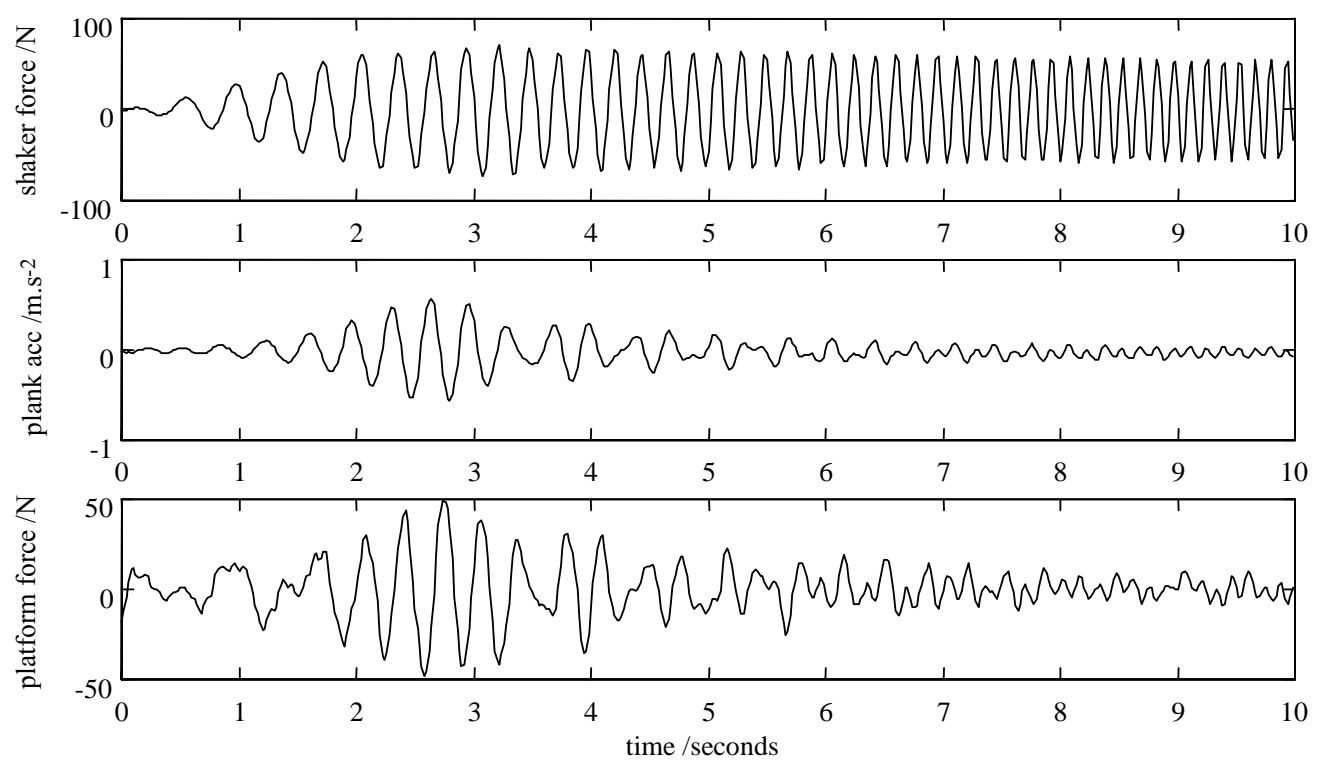

Fig. 2. Measured signals for subject standing on plank.

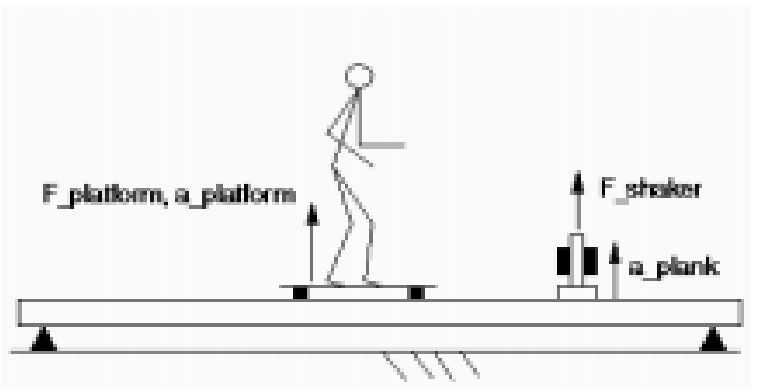

Fig. 3. Schematic of test arrangement. Velocities $v_{\text {plank }}$ and $v_{\text {platform }}$ were obtained from accelerations a-plank and a platform using Simulink 1/s integrator.

for no occupant (bare plank) and with the equivalent solid mass.

The result is clear and not unexpected. The frequency decreases to a different degree as if effective mass is increased, while the damping ratio increases significantly, depending on posture. The reduction in frequency is greater than when using a dead weight and this is consistent with the description of a human as a single degree of freedom (SDOF) system.

For one situation, with knees very bent, the fundamental frequency reverted to the value for the bare plank \pm a few $\%$ together with a very high damping ratio. While a little artificial, the situation is not so easily explained using simple SDOF models with constant parameters and there may be some active participation of the occupant.
In most practical situations, the frequency reduction effect of humans not acting as load generators will not be so important as will be the dampening effect. The research reported here is an investigation of this effect through study of the energy dissipation in the system.

Note that the subjects included the author and a student, both of whom willingly participated in the research.

\subsection{Energy and power balance}

Power is rate of change of energy and it is through measurements of instantaneous power that energy is determined, hence:

For the plank system the power balance is:

Power supplied by

(i) $=F_{\text {shaker }} \times v_{\text {plank }}$

shaker

$=$ power dissipation

due to plank internal

(ii) $=2 \zeta \omega \times m m \times v_{\text {plank }}^{2}$ damping

+ power dissipation (iii) $=F_{\text {platform }} \times v_{\text {platform }}$ due to human

+ net rate of supply

of energy $(\mathrm{KE}+\mathrm{PE})$

to plank

Where

$m m=$ effective(modal) mass of plank,

$\omega \quad=$ plank first mode natural frequency $(\mathrm{rad} / \mathrm{s})$,

$\zeta=$ plank modal damping ratio and plank velocities for shaker power and plank damping depend on mode shape. 


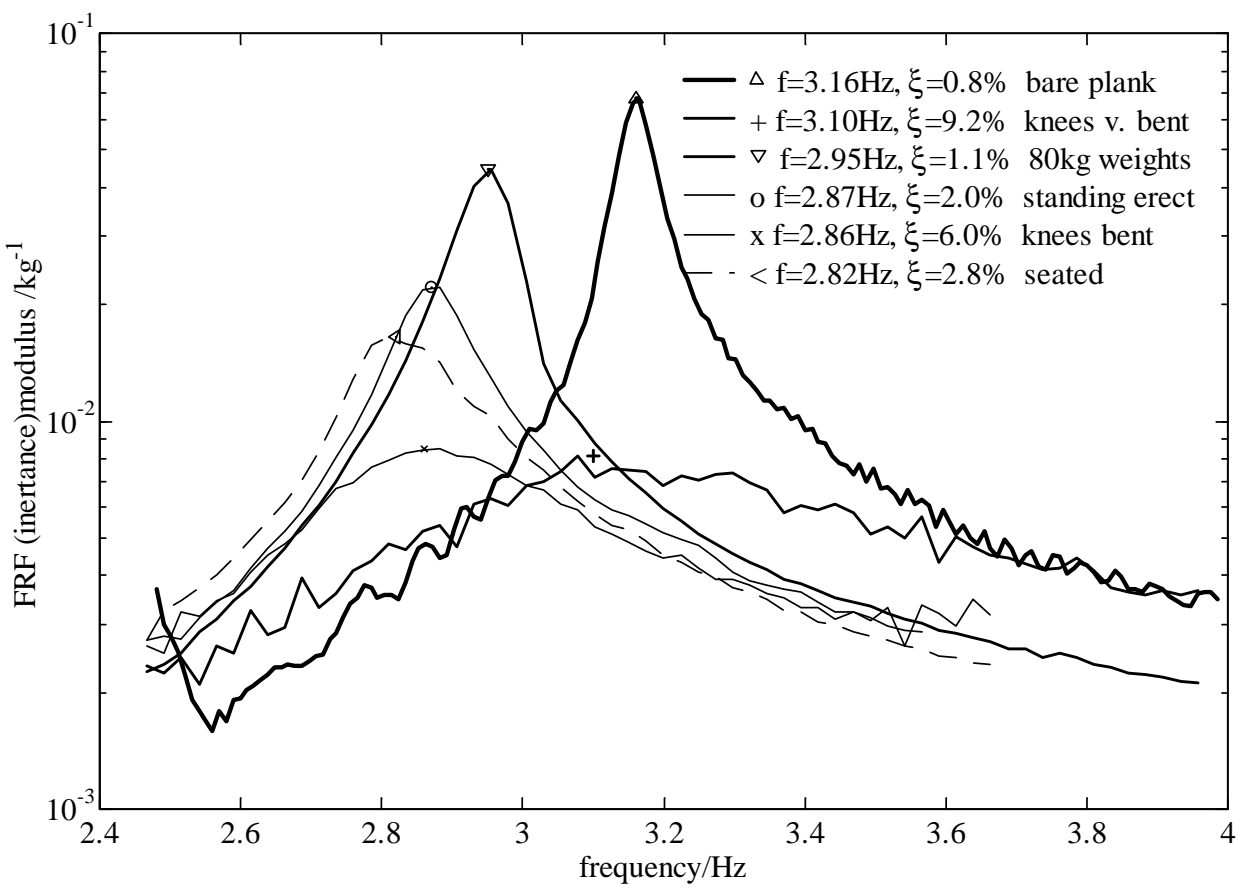

Fig. 4. Frequency response functions (FRFs) for various dead and live loads. Symbols identify natural frequencies on respective FRF curves.

In fact it is the energy balance, which is the time integral of all the above quantities that is presented here. These calculations were done using Simulink [11] on data such as shown in Fig. 2. To convert from acceleration to velocity the ' $1 / \mathrm{s}$ ' integrator was used, preceded by high pass filtering. For the fundamental mode of interest in this study, at $3.16 \mathrm{~Hz}$ with $0.8 \%$ damping, the mode shape $\phi(x)$ is practically a pure sinusoid and the modal mass estimated through modal analysis of the experimental FRF is consistent with the modal integral:

$$
m m=\int_{0}^{L} \phi^{2}(x) m(x) d x
$$

for a mass per unit length $m(x)$ over length $L$ and including the mass of the shaker body factored by appropriate modal ordinates. For the fundamental mode, $m m=675 \mathrm{~kg}$, and the modal stiffness and damping parameters $k=266 \mathrm{kN} / \mathrm{m}$ and $c=201 \mathrm{Ns} / \mathrm{m}$ follow.

Figures 5(a), (b) and (c) show respectively the energy balance (from time integral of components $i$, ii and iii) for the first 10 seconds of the signal passing through the first mode for the case of a person standing erect, standing with knees slightly bent and standing with knees very bent (and very tiring). Figure 5(d) shows the balance for the bare plank; the difference between the two curves is largely accounted for by stored energy $(\mathrm{KE}+\mathrm{PE})$.
Passing through resonance, energy dissipation by the human subject is, depending on posture, several times that due to the plank itself, dramatically increasing the effective damping of the human-structure system.

\section{Mathematical model}

Based on the assumption that the human and the plank behave essentially as a two degree of freedom (2DOF) system, a 2DOF model was used to simulate the behaviour of the plank and the energy path through the system.

The multi-degree of freedom human body model proposed by International Standards Organisation [8], whose parameters are indicated in the upper view of Fig. 6, was analysed to determine the natural frequencies and damping ratios of the human alone, and of the human-plank system. For the human-plank system the modal mass, stiffness and damping quantities for the plank were taken corresponding to the point of contact (where the subject stood) on the midpoint of the plank.

For the human alone the eigenvalue solution of the ISO model yields a fundamental mode:

$$
f_{\text {human }}=4.88 \mathrm{~Hz} \text { and } \xi_{\text {human }}=37 \% \text {. }
$$

For the plank and (ISO) human together, the values are: 


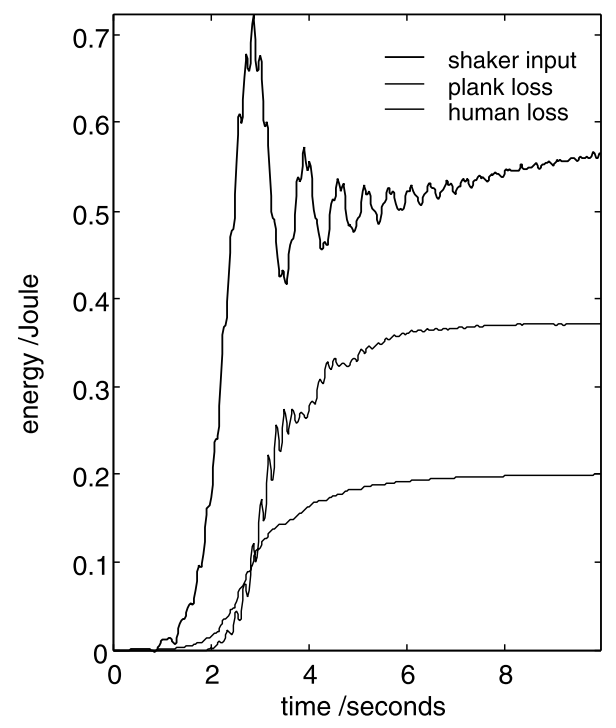

a) human standing straight (erect)

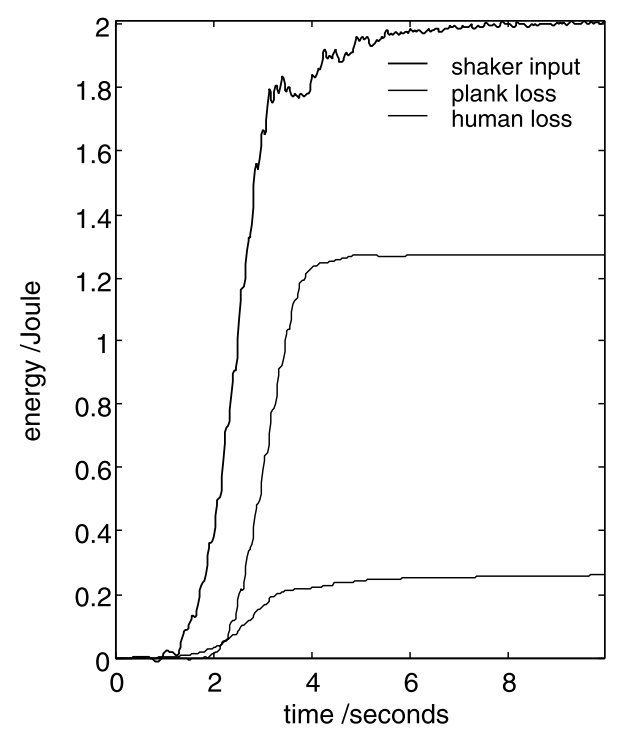

c) standing with knees very bent

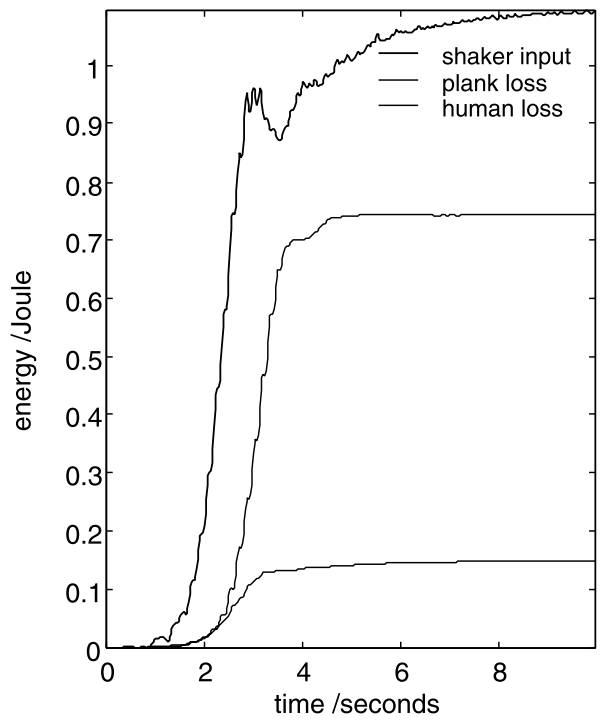

b) standing with knees slightly bent

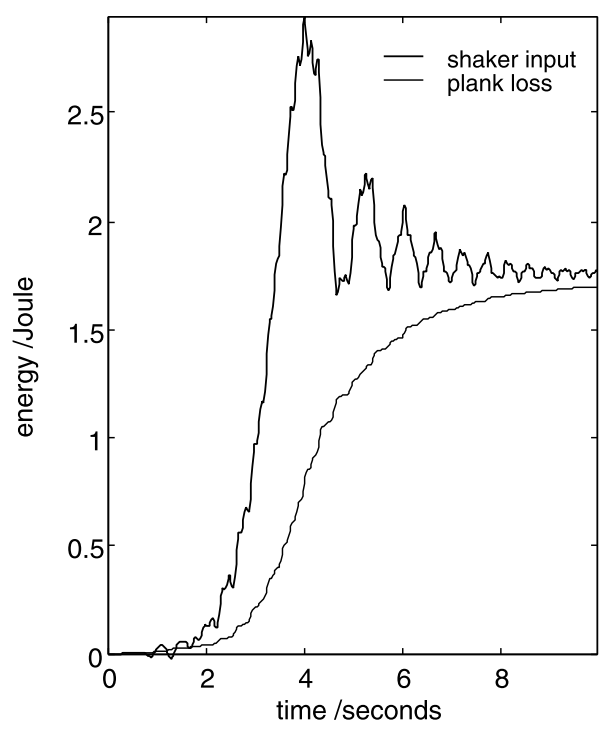

d) bare plank

Fig. 5. Energy balance for plank during first 10 seconds of chirp excitation passing through first resonance. a) human standing straight (erect), b) standing with knees slightly bent, c) standing with knees very bent, d) bare plank.

$$
f_{\text {plank }}=2.93 \mathrm{~Hz} \text { and } \xi_{\text {plank }}=2.2 \%
$$

for the mode where the plank vibration dominates,

$f_{\text {human }}=5.32 \mathrm{~Hz}$ and $\xi_{\text {human }}=36 \%$

for the mode where human response is most

significant

These are consistent with the experimental data shown in Fig. 4.
Due to the non-proportional damping matrix, the ISO model is not in a form that can be converted to a set of decoupled normal modes. Nevertheless, equivalent modal damping mass and stiffness values for the human were estimated from the first mode of the ISO human model as parameters for a SDOF human model, and are shown in the lower view of Fig. 6. Combining this approximation with the plank model to derive a two degree of freedom (2DOF) model, the plank/human sys- 


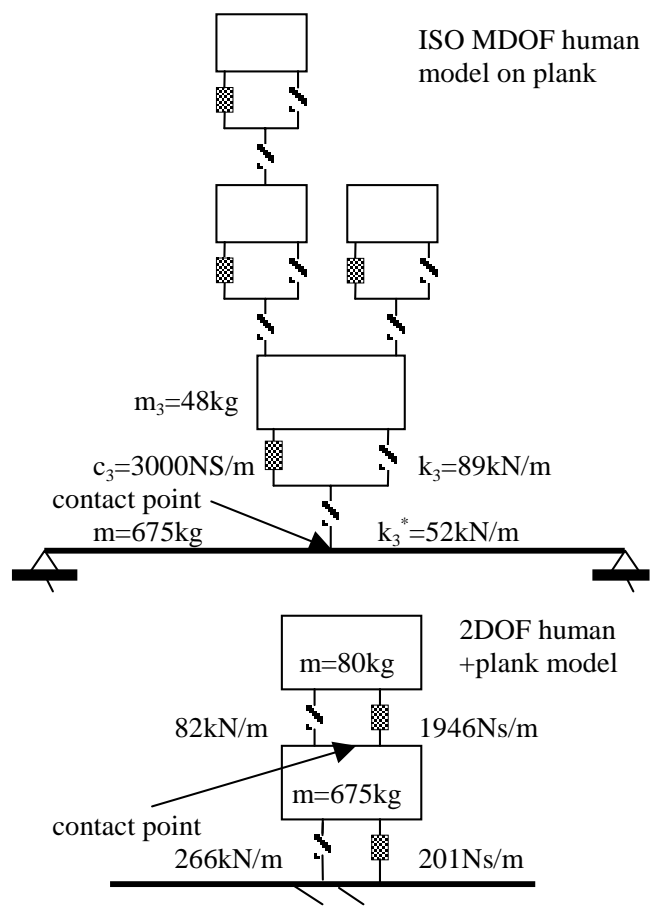

Fig. 6. Equivalent multi-degree of freedom (MDOF) systems for human and human-plank system. Forces between human and plank are transmitted at the indicated contact point.

tem has two modes, one with mainly plank movement, one mainly human:

$$
\begin{aligned}
& f_{\text {plank }}=2.93 \mathrm{~Hz} \text { and } \xi_{\text {plank }}=2.0 \% . \\
& f_{\text {human }}=5.27 \mathrm{~Hz} \text { and } \xi_{\text {human }}=36 \% .
\end{aligned}
$$

There are some minor differences but the 2DOF model could be an acceptable simplification. The 2DOF model of Fig. 6 was used in a 'controlled' simulation (using Simulink) of the physical experiment and Fig. 7 shows the resulting energy balance. The trend is similar to the experimental version (Fig. 5(a)) but the energy dissipated by the subject is a smaller proportion of the total.

While this study is aimed at a different application, it is worth noting studies by Lundstrom et al. [9] considering energy absorption of vertically vibrating seated humans. Recent research [3] shows different dynamic effect (e.g. damping) when the subject is relaxed and that damping of seated humans can be almost as much as for standing humans.

The above analysis does not 'prove' that the human behaves as the reduced ISO model; it is consistent. It is notable that even after many years of research there is still no clearly identified SDOF human model. Experimental results reported by Griffin [7] and empiri-

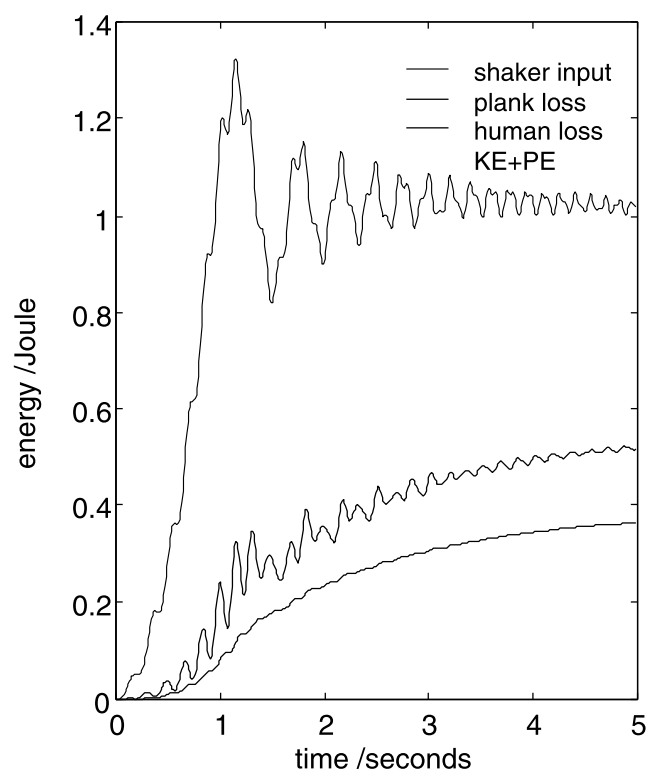

Fig. 7. Simulated energy balance for standing human.

cal models due to ISO [8] give values of around $5 \mathrm{~Hz}$ and these are built into the human vibration tolerance standards [2], yet more recent research [10] suggests higher values, in the region of $10 \mathrm{~Hz}$.

Although there are several ways to estimate an equivalent human SDOF model, one possible method applied through measurements of the ratio of force and acceleration at the human/structure interface (e.g. shoes) is curve fitting of the SDOF apparent mass. One set of data for a $47 \mathrm{~kg}$ subject is shown in Fig. 8. The subject mass is overerestimated as $60 \mathrm{~kg}$, so the damping ratio is also too high, but the frequency is clearly in the 5$6 \mathrm{~Hz}$ range. Direct methods of realising the equivalent 2DOF system e.g. by using the eigensystem realisation algorithm with the vibration time histories should be promising.

\section{Full scale evidence: Function hall}

There are numerous examples of human-induced floor vibrations and their assessment in the literature [1, 12,13]. What is more interesting is study of experiments where the mitigating effects of humans are observed.

A common structural serviceability 'problem' is floor vibrations excited by coordinated jumping of a crowd of people on a lightweight floor. Less well understand is the situation where many people are present 
new3 ${ }_{m}$ at ch4/ch1 mod, $\phi, f, \xi=60.8305,-130.4209^{\circ} 5.7969 \mathrm{~Hz}, 38.0406 \%$

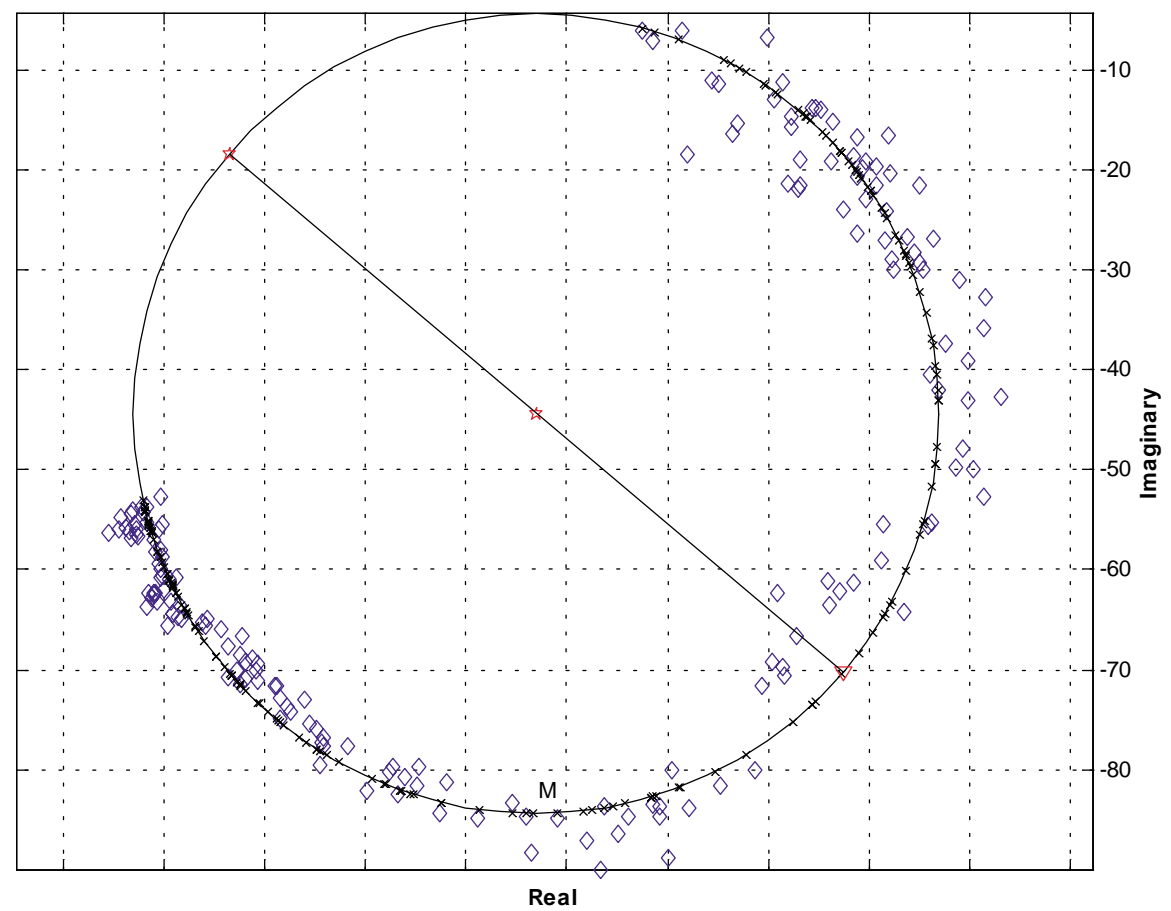

$\operatorname{Mod}(\operatorname{RE})=\psi_{i} \cdot \psi_{j} / \psi^{\top}[\mathrm{m}] \psi$

$\operatorname{Mod}(\mathrm{TF})=\psi_{\mathrm{i}}[\mathrm{m}] \cdot \psi^{\prime} / \psi^{\top}[\mathrm{m}] \psi=\operatorname{psi}_{\mathrm{i}} L /$

Fig. 8. Circle fit to apparent mass frequency response function for $47 \mathrm{~kg}$ standing human.

but not all participate, and where those who do jump are not well synchronised.

Figure 9 shows the FRF of a composite floor with an estimated effective (modal) mass of 75 tonnes. The floor has free spans of $20.4 \mathrm{~m}$ and $22 \mathrm{~m}$ and comprises one-way spanning steel beams supporting metal (Bondek) decking with integral reinforced concrete slab. The supports are not symmetric since one edge joins an adjacent smaller slab while the soffit features a grid of tracks for moving partitions around for the floor below. These partitions are locked in place by a wedging mechanism leading to partial vertical restraint and with the arrangement of partitions at the time of the measurements the floor had a fundamental frequency at $7.28 \mathrm{~Hz}$ with damping approximately $3 \%$ when unoccupied. The FRF was obtained using the same equipment as for the plank experiment.

The resonant frequency could also be excited by synchronised jumping. Figure 10 shows the acceleration (root) power spectral density (PSD) of response to four people jumping in unison at a rather slow frequency of approximately $1.9 \mathrm{~Hz}$, generating response at the fundamental, 2nd harmonic, 3rd harmonic (weakly) and at

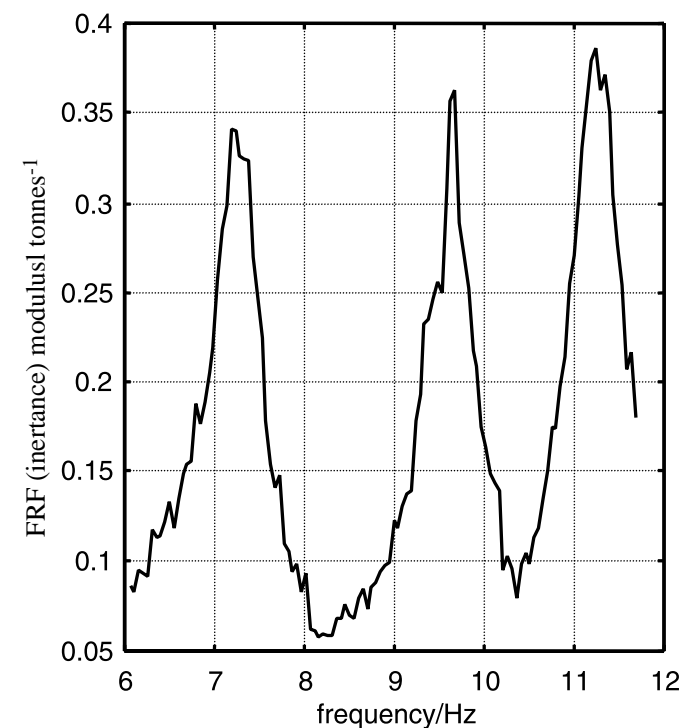

Fig. 9. FRF for bare composite floor.

the 4th harmonic (strongly) through resonant amplification.

While the four people were jumping to generate the 


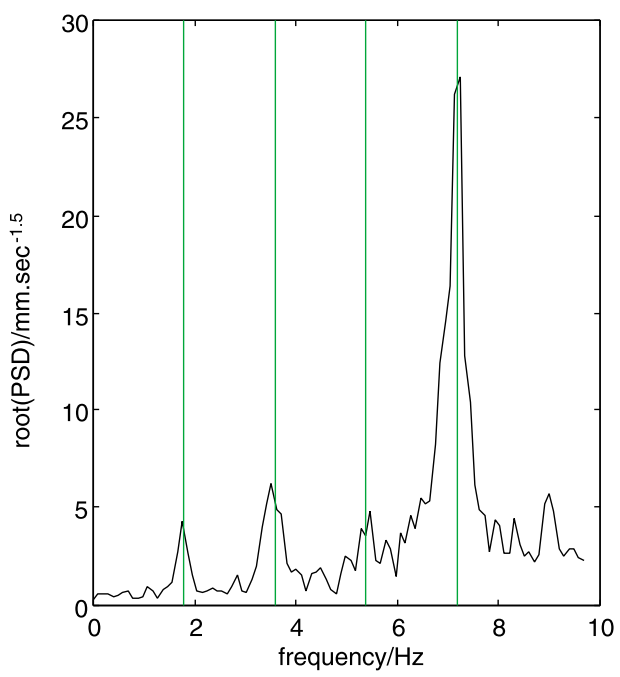

Fig. 10. Floor response to slow jumping by four people-bare floor.

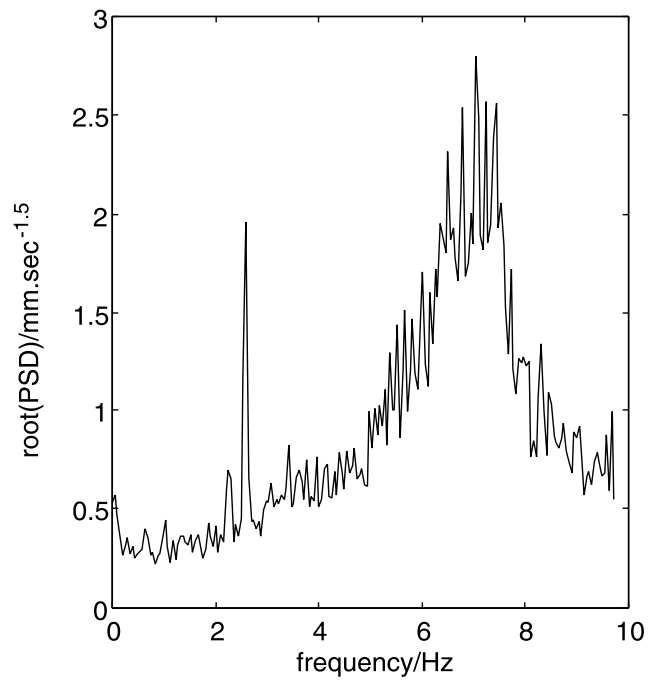

Fig. 11. Floor ambient response with seated crowd.

response of Fig. 10, the floor was otherwise unoccupied. Measurements of low level (background) response when occupied by a church congregation of some 400 seated people listening to a sermon showed a very heavily damped resonance around $6.6 \mathrm{~Hz}$ (Fig. 11). Figure 12 shows the PSD of floor response with many of these 400 people jumping fast while others simply stood or sat and watched. There are two sequences of jumping with different beat frequencies and the fundamental and harmonics are shown, none of which significantly excite the floor in resonance. This is evidence that the 'static' observers provide a mitigating effect on a potential resonant condition.

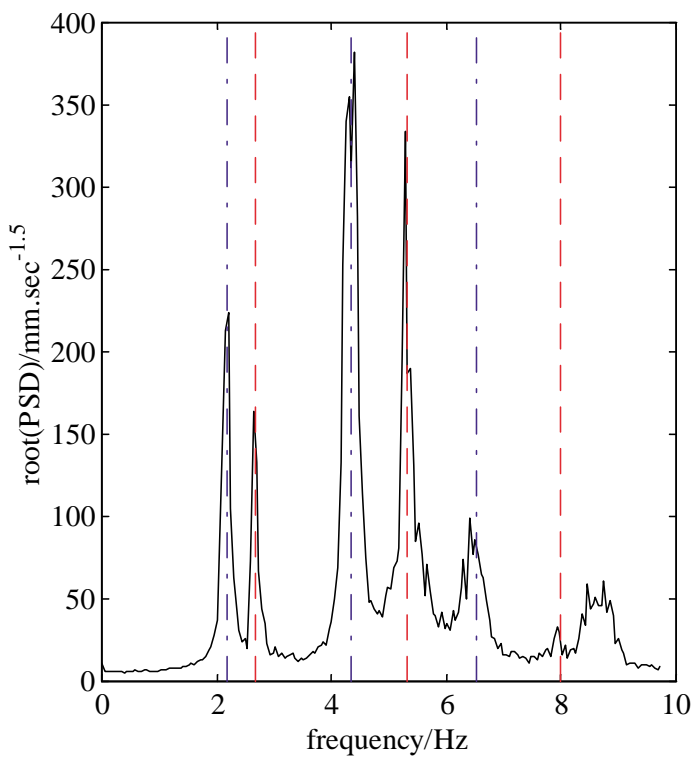

Fig. 12. Floor response to fast jumping by a large crowd-with seated occupants.

\section{Discussion and conclusions}

Tests on human-structure interaction in a laboratory have confirmed findings elsewhere that the human body acts dynamically with the structure in a way that modifies the natural frequency of the structure while greatly increasing the damping capacity, even when seated.

Measurements of the response have been able to show the energy path from the source to the strongest damping element, the human occupant.

Numerical simulations using a published multidegree of freedom human model condensed to a single degree of freedom model corroborate the experimental findings, with some minor differences, and this is one route to study the problem, particularly if the parameters in the SDOF model could be identified for different postures.

The beneficial damping effect of humans present on a floor while others are providing the vibration source requires further investigation, and further evidence. It is not at present a factor likely to be accepted by certifying authorities studying floor structural designs for serviceability.

The study is being extended to include lighter and higher frequency planks, to find the most convincing means of finding an equivalent SDOF human dynamic model for mitigating effects on vertical floor vibrations, and to investigate in more detail the different effects of sitting and standing with a larger group of subjects. 


\section{Acknowledgements}

The author acknowledges the helpful advice from Dr Tianjin Ji, and the assistance of final year and research students Teo Seng Chuan and Zheng Xiahua in the experimental work.

\section{References}

[1] H. Bachmann, Case studies of structures with man-induced vibrations, Journal of Structural Engineering ASCE 118(3) 1992.

[2] British Standards Institution, Evaluation of human exposure to vibration in buildings $(1 \mathrm{~Hz}-80 \mathrm{~Hz}), \mathrm{BS} 6472,1992$.

[3] J.M.W. Brownjohn and X. Zheng, The effects of human posture on energy dissipation from vibrating floors, Second International Conference on Experimental Mechanics, Singapore 29/11-2/12/2000, 2000.

[4] British Standards Institution, Code of practice for dead and imposed loads, BS6399, Part 1, 1997.

[5] B. Ellis and T. Ji, Human actions on structures, Society for
Civil Engineering Dynamics Newsletter 9 No. 3, Institution of Civil Engineers, UK, 1995.

[6] B.R. Ellis and T. Ji, Human-structure interaction in vertical vibrations, Buildings and Structures, Proceedings Institution of Civil Engineers 122 (1997), 1-19.

[7] M.J. Griffin, Handbook of human vibration, Academic Press, London, 1990.

[8] International Standards Organisation, Mechanical vibration and shock - Mechanical transmissibility of the human body in the $\mathrm{z}$ direction, ISO 7962, 1987.

[9] R. Lundstrom, P. Holmlund and L. Lindberg, Absorption of energy during vertical whole-body exposure, Journal of Biomechanics 31 (1998), 317-326.

[10] J.M. Randall, R.T. Matthews and M.A. Stiles, Resonant frequencies of standing humans, Ergonomics 40(9) (1997), 879_ 886.

[11] The MathWorks Inc., Using Simulink. Dynamic systems simulation for Matlab® ${ }^{\circledR}, 1997$.

[12] M.S. Williams and P. Waldron, Evaluation of methods for predicting occupant-induced vibrations in concrete floors, The Structural Engineer 72(20) (1994), 334-340.

[13] T.A. Wyatt, Floor excitation by rhythmic vertical jumping, Engineering Structures 7 (1985), 208-210. 

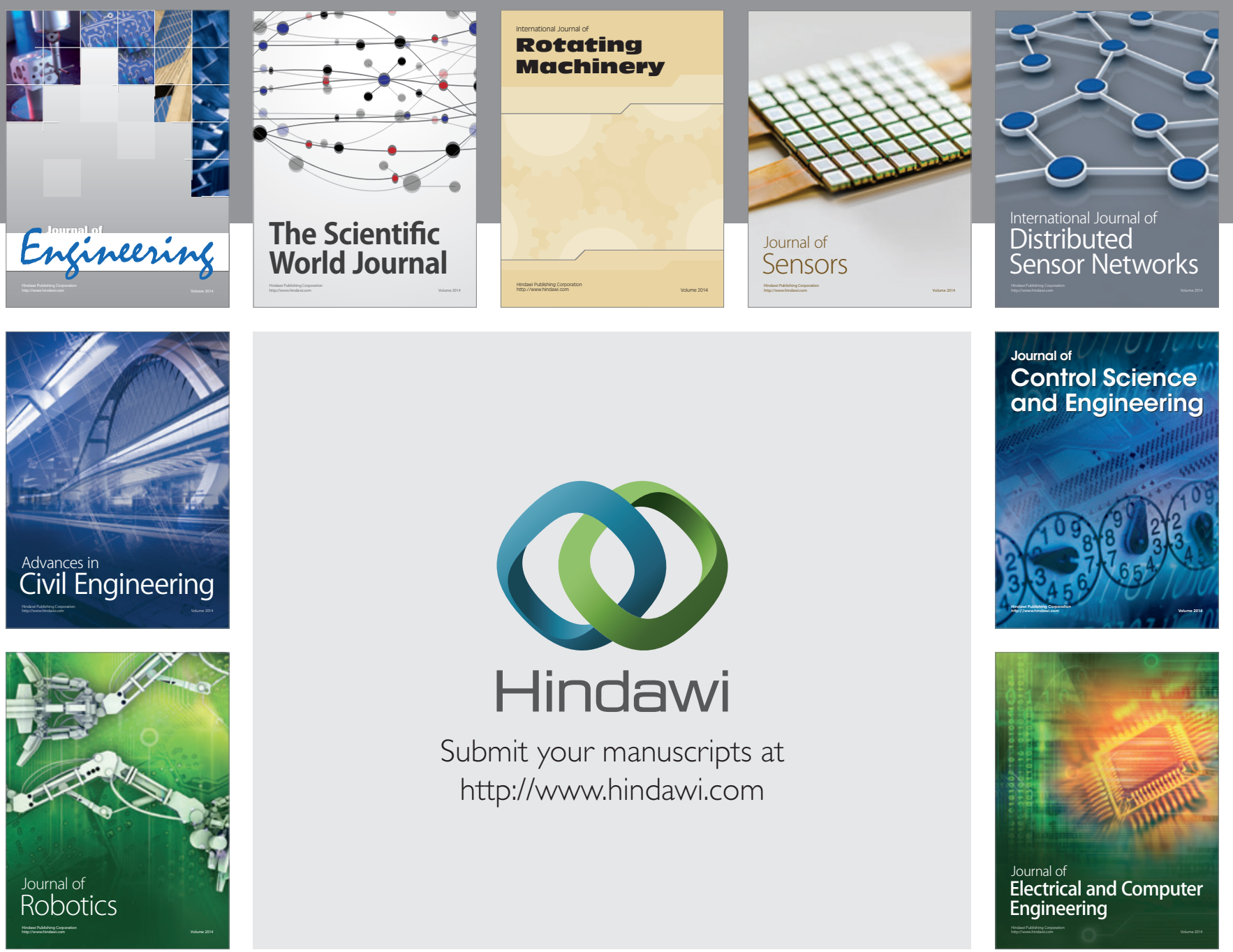

Submit your manuscripts at

http://www.hindawi.com
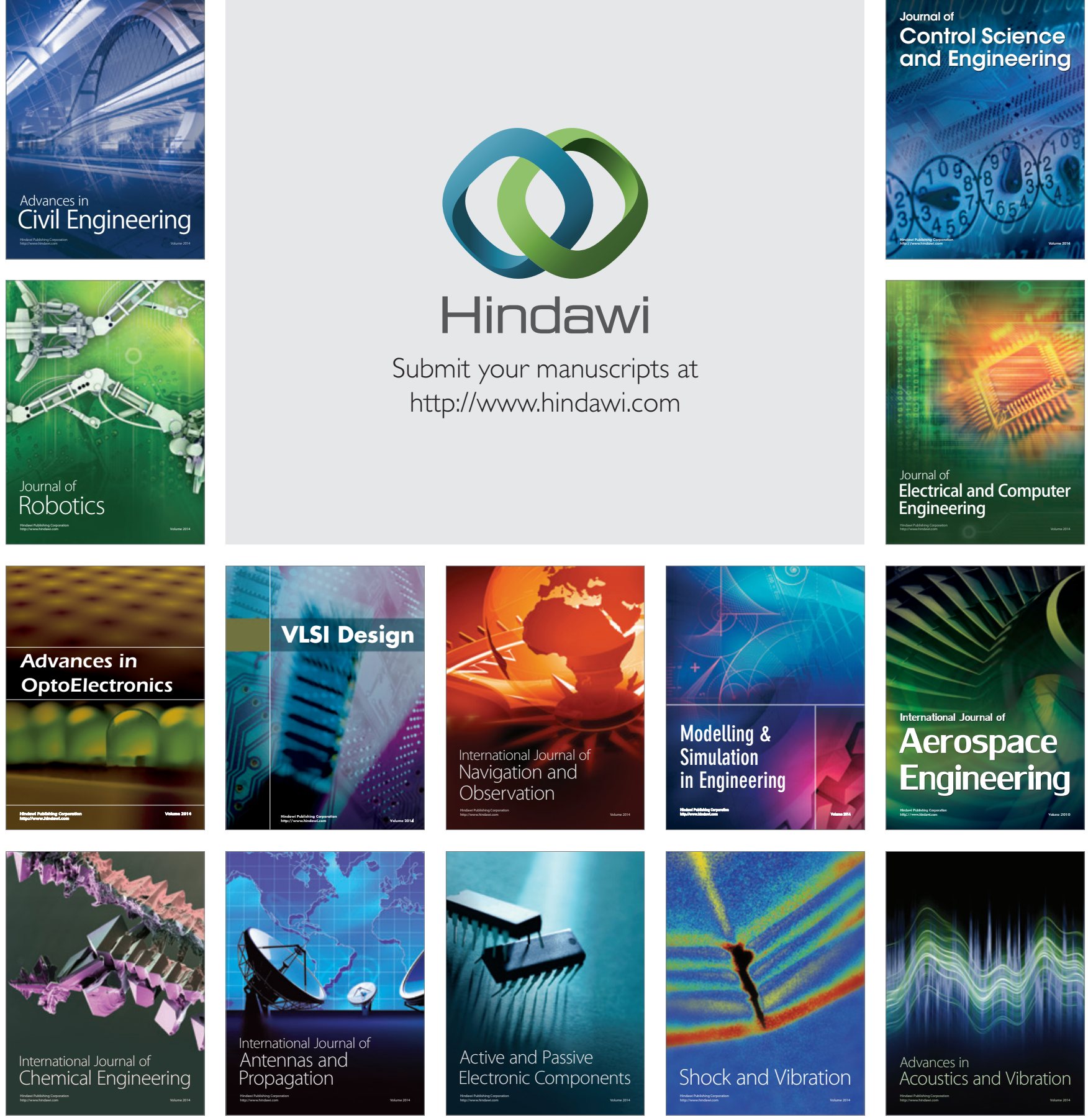